\title{
PALAVRAS PARA DONA DIRCE
}

Silviano Santiago

(UFF)

Sempre confiei no Acaso.

E foi por acaso que, ainda na cidade de Formiga, antes de mudar para Belo Horizonte em 1948, soube e muito sobre o Instituto Lafayette, educandário carioca localizado na longínqua Rua Haddock Lobo, na Tijuca. Meu pai teve onze filhos e os mais velhos não tinham como dar continuidade aos estudos na provinciana cidade do oeste mineiro. Optou, então, por enviá-los à capital federal. Seu plano deve ter sido influenciado pela presença de irmão dele - por parte de mãe -, morador da rua 19 de Fevereiro, em Botafogo. Ele e a esposa, que trabalhava na importação de peles da Casa Canadá, poderiam espreitar os sobrinhos longe da casa paterna. Lembro também de preferência na sua leitura diária. Em Formiga, era assinante de $O$ correio da manhã, e não de $O$ Estado de Minas, jornal belo-horizontino dos Diários Associados. A opção pelo Rio de Janeiro talvez ainda se justifique pelo fato de ter origem nas Gerais a família do educador à frente do Instituto Lafayette. Pessoa de confiança.

Por volta de 1948, meu pai paga a passagem e os estudos da filha mais velha, formada na Escola Normal Oficial de Formiga. No Rio de Janeiro, deve aperfeiçoar-se com o professor espanhol Mira y Lopez, ex-militante da Unió Socialista de Catalunya que, durante a Guerra Civil Espanhola, foi chefe dos serviços psiquiátricos do exército republicano. Exilado pelas razões que a História dos anos 1930 explica, percorre vários países até bater à porta do Brasil. Minha irmã faz parte do grupo que funda o Instituto de Seleção e Orientação Profissional (ISOP). Ela regressará posteriormente a Belo Horizonte e, com colegas, será corresponsável pela implantação de serviço semelhante em Minas Gerais.

Não competiria mais ao patriarca da família definir a profissão do filho. Aplicados com diligência e rigor por especialistas, a bateria de exames psicotécnicos propicia um Psicodiagnóstico Miocinético que melhor avalia o potencial do perfil intelectual do adolescente, ou pós-adolescen- 
te, e serve para estimular a família a encaminhá-lo a profissão compatível com seu interesse e vontade, ou afim a eles.

Um pouco antes, em 1945, se não me engano, meu pai tinha enviado o filho mais velho ao Rio de Janeiro para cursar o científico como aluno interno no Instituto Lafayette. Santiago Filho acaba por seguir a profíssão do pai, cirurgião-dentista, mas traz muitas novidades da capital federal para a cidade provinciana. Três pelo menos, além do sotaque ligeiramente acariocado. Um dos livros adotados numa disciplina do curso clássico e científico oferecido pelo Instituto Lafayette. Um interesse desmedido por filmes de qualidade, incentivado que fora a assisti-los pela boa crítica cinematográfica publicada nos jornais cariocas de então. Last but not the least, um distintivo do Botafogo (o clube da estrela solitária). Anti-getulista, como rebelde que se preza, ele ostentará posteriormente na lapela o distintivo do Clube da Lanterna.

Interessei-me de imediato e volto a me interessar pelo livro didático adotado no Instituto Lafayette. Trata-se de Unidades literárias - história da literatura brasileira, destinado à $3^{\mathrm{a}}$ série do antigo curso clássico e científico. Escrito por Virgínia Côrtes Lacerda, sua professora de Língua Portuguesa, o manual fora publicado em 1944.

Como detectava meu interesse por ficção, no sentido amplíssimo do termo, pois naquela época só gostava de ler gibis e de ir ao cinema, e tendo observado na professora o interesse constante pelo diálogo interativo com o estudante, meu irmão me entregou o exemplar do livro usado no curso, dizendo-me que muito aproveitaria se lesse os textos literários que constavam da antologia (que se encontra ao final do volume, se não me engano). Fora importante para ele lê-los no internato e discuti-los em sala de aula. Além do mais, eu me preparava ainda em Formiga para fazer o exame de admissão ao Colégio Estadual, em Belo Horizonte.

Não consigo lembrar-me das nossas conversas, mas não posso esquecer o fato de que havia no irmão mais velho uma predisposição à atividade didática junto ao menos preparado e curioso da literatura, e ela se manifestou claramente no incentivo ao meu acesso à literatura e, posteriormente, ao cinema como arte. Ele é quem me encaminha, agora por volta de 1952, ao Centro de Estudos Cinematográficos (CEC), aonde vim a conhecer meu primeiro mentor literário, Jacques do Prado Brandão, e onde travei amizade com os vários e futuros membros da geração Complemento.

Se os irmãos mais velhos foram estudar no Rio de Janeiro, por que um dia o do meio não iria se aperfeiçoar em Paris? - eis a pílula de 
vida do Dr. Ross soprada pelo acaso.

Dona Virgínia, assim meu irmão chamava a mestra, era prima da professora Dirce Côrtes Riedel, vim a descobrir já na Faculdade de Letras em 1956, quando comecei a ler tardiamente Machado de Assis. Naquela época, a literatura brasileira era oferecida apenas no terceiro ano do curso de Letras Neolatinas. A publicação do livro O tempo no romance machadiano, de dona Dirce, coincidiu com meu terceiro ano e a decidida opção pela literatura em detrimento do delírio juvenil pelo cinema. 1959.

É pelo caminho traçado pelo acaso na minha infância e juventude que chego a um dos traços mais salientes da personalidade intelectual de dona Dirce. Ela pertence a família de educadores. Nas Faculdades ou Institutos de Letras, até pela novidade que a especialidade representa em termos da curta história da Universidade no Brasil, a maioria dos diplomados e dos professores são freelancers. Emergem dum surpreendente e todo-poderoso nada que ainda na pós-adolescência se torna tudo. Noutro contexto, Fernando Pessoa o disse melhor, abusando do atrevido oximoro: "O mito é o nada que é tudo!".

Frente ao futuro incerto da profissionalização em país de maioria analfabeta, não sabemos bem por que fazemos vestibular para Letras. E prosseguimos sem nos darmos conta do que nos espera depois da eleição pelo estudo, ensino e pesquisa em literatura. Sabemos que amamos a literatura e as artes em geral, e temos certeza de que não é mais aconselhável separar-se do objeto amoroso de estudo na época da institucionalização da Universidade no Brasil. Exige-se cada vez mais que o jovem universitário se especialize.

E por muito amar à disciplina (simplifico, apelidando assim o objeto do nosso amor), acabamos todos nos enfronhando por ela anos a fio, como, antes de nós, profissionais formados em Direito, Medicina, Engenharia e mais padres e ex-seminaristas e ainda freiras e ex-noviças nela se especializaram para serem professores e professoras de Letras. Nos professores e professoras de literatura que conheço avalio que é mais importante - no tocante à inserção deles e delas nisto a que se chama de ensino e pesquisa em literatura - o talento individual do que a própria emersão duma tradição familiar, de que o jovem profissional faz parte e participa desde o berço.

Dona Dirce emerge de bem assentada tradição familiar. Seu pai é o professor Lafayette Côrtes, fundador e diretor do famoso educandário que leva seu nome. 
Vocações para a docência não se definem pelos mesmos critérios. Falei da minha, produto do acaso. Falo da vocação de dona Dirce e de seus interesses maiores, despertados sem dúvida pelo convívio cotidiano com a família de educadores. De imediato, saliento três pontos da sua carreira: (1) o interesse pela formação lenta e gradativa do estudante (neste sentido, a divisão proposta por dona Virgínia entre unidades didáticas e o todo da literatura é capital), ${ }^{1}$ (2) a dedicação prioritária à leitura do texto literário como processo de descoberta do lugar ocupado no mundo pelo indivíduo em formação, com ênfase menos intensa na pesquisa setorizada em teoria literária, e (3) o desempenho iluminista do mestre em sala de aula e fora dela - sua performance, diria hoje - como principal requisito ético da docência.

A sala de aula não é o lugar sine qua non na concepção ética da profissão de docente. Se o fosse, a tarefa do professor reproduziria apenas o baby-sitting system pequeno-burguês, ${ }^{2}$ que é de responsabilidade exclusiva da formação familiar do estudante. Ali, nas salas de aula da Faculdade de Letras, se passa apenas a parte imóvel da atividade professoral que muitas vezes, na geração de dona Dirce, se confundia com o mero dizer dramático dos poemas e de trechos em prosa dos grandes autores nacionais e portugueses. Refiro-me à reduplicação em sala de aula do trabalho interpretativo do português João Villaret ou da poliglota argentina Berta Singerman nos palcos de teatro. Professor não é diseur. Aluno não é espectador. A presença de mestre e alunos na sala de aula é apenas, embora também não se possa dizer que seja unicamente, o indispensável requisito burocrático.

A atividade em sala de aula tem de vir associada à movimentaçãoviva dos reencontros entre docente e discente - seja na própria instituição, sob a forma de palestras, conferências ou simpósios, seja na residência do mestre. Esta passa a ser complementar à Universidade, pois tem a função de lugar onde trona a biblioteca rica e atualizada (que a instituição brasileira ainda não oferece). A residência da mestra em Copacabana - no universo pequeno-burguês carioca - foi também o lugar por excelência do debate descontraído e aprofundado, onde a distinção entre mestre e discípulo é definitivamente apagada.

Não tive o privilégio de participar da movimentação-viva propiciada pela moderna e revolucionária pedagogia de Dona Dirce. Cheguei tarde ao seu convívio, embora tenha chegado cedo à influência da família de educadores na vida escolar que compartilho com meu irmão mais velho. 
Mas muitos dos estudantes e futuros colegas meus - aos quais dedico este perfil - tiveram o privilégio e são unânimes em salientar o carinho muito especial com que a professora conduzia as atividades extracurriculares. Nas reuniões informais pipocavam também - sem o alarde do escândalo, mas no tom correto do interesse pela atualidade - as graves e sofridas questões sociais e políticas que por anos tornaram a nação brasileira quase inabitável pelos cidadãos verdadeiramente responsáveis.

Talvez tenha me equivocado ao insistir no fim da distinção entre mestre e discípulo. E mais me equivoquei ao caracterizá-lo pelo advérbio definitivamente. Numa personalidade sentimental (no sentido flaubertiano do termo) e intelectual tão rica quanto a de Dona Dirce, não faz sentido crer que ela não se entregasse, no trato pessoal e íntimo com a literatura no seu escritório de trabalho, a longos momentos de silêncio, abandono e solidão, em contato com a imensa, riquíssima e variadíssima biblioteca. Biblioteca que tinha - no entanto e no fundo - mais importância para a sala de aula do que para a mulher inteligente e reflexiva no gabinete de estudo. Digo isso porque sei que esses momentos de silêncio, abandono e solidão são dominados ditatorialmente pelas enigmáticas obsessões que constroem a contribuição original do docente/pesquisador à disciplina.

Naqueles momentos especiais, Dona Dirce se dedicava única e exclusivamente aos pouquíssimos romancistas que julgava os mestres da prosa literária no Brasil. Foram dois principalmente. Machado de Assis e Guimarães Rosa. Com ligeira abertura para outros dois: o poeta Jorge de Lima e o romancista Autran Dourado.

A distinção nítida entre professor e alunos, e sua negação, é importante não só para conhecer de modo mais amplo a atividade docente de Dona Dirce, mas também para enfrentar com conhecimento de causa as atividades historiográficas e críticas - numa palavra, editoriais - alavancadas pela mestra. Não havendo distinção entre docente e dicente, o trabalho era coletivo e, ao mesmo tempo, teria de ser geral e abrangente - dar conta do todo da História da literatura brasileira nas suas manifestações mais importantes.

Naquela época, os grupos de trabalho orientados por Dona Dirce, e é a isso que estou me referindo, respondiam à pergunta Como e para que ensinar a leitura?, e se interessavam menos por outra, mais delicada e atual, Como e para que pesquisar a teoria da literatura?. Os participantes dos grupos de trabalho tinham, indistintamente, o nível almejado para se tornarem colaboradores. 
Estou me referindo evidentemente a algo que existe e é concreto. Os vários livros de caráter paradidático derivados estritamente da docência, no sentido amplo, da Dona Dirce. Refiro-me à Literatura brasileira em curso (1968), à Literatura portuguesa em curso e finalmente à Leitura de Invenção de Orfeu (os dois últimos datados de 1975). Como produtos do trabalho de equipe, os três livros vêm assinados por vários e diferentes autores. A assinatura Dirce Cortes Riedel não é absoluta; é uma entre muitas.

Se me permitem um perigoso anacronismo, a mestra universitária retomava e atualizava as unidades didáticas tal como afirmadas e afinadas nos cursos clássico e científico por Dona Virgínia. As antigas unidades literárias que ainda hoje podem ser desentranhadas com proveito da organização e redação dos seus dois livros pioneiros. Elas serviram e ainda servem para desbancar para sempre a predominância, como manual do ensino secundário em Letras, das histórias da literatura à moda do francês Gustave Lanson.

A memorização da biografia dos principais escritores e do resumo ufanista dos seus livros é substituída pela leitura da obra, ainda que apenas em extratos representativos. A docência passa a ter como modelo o método de leitura chamado de "explication de texte", oriundo dos bons liceus franceses e, a partir dos anos 1950 no Rio de Janeiro, do new criticism anglo-saxão. O novo modelo docente não tinha, no entanto, o caráter empobrecido de mera leitura do texto pelo texto. As unidades literárias se faziam acompanhar de sentido pragmático (uso o vocábulo de dona Virgínia, para quem a dominante da docência era a relação estreita entre profesor, literatura e experiência de vida do estudante) que organiza desorganizando - para o aluno os conceitos tradicionais e intuitivos que recebe seja da família ou da sociedade conservadora, subvertendo-os. No caso dos dois volumes da "literatura em curso" (hoje fariam mais sentido se ditos online), o pragmatismo docente está na seleção dos textos por temas progressistas: povo, trabalho, liberdade, amor...

As obsessões enigmáticas do docente/pesquisador encaminharam Dona Dirce às obras de Machado de Assis e de Guimarães Rosa, principalmente. No escritório, sob a luz do abajur, o conhecimento da literatura e sua transmissão em sala de aula se tornam reflexão íntima e secreta sobre dois dos mais notáveis escritores brasileiros que dedicam a própria Vida às chamadas Belles lettres. Grafo a expressão em francês, para realçar o caráter elitista e gratuito das obsessões enigmáticas, se por acaso se pode apelidar 
de elitista e gratuito o desejo de melhor se aproximar - através das artes do que existe de humano e de animal, de corpo e de espírito, de divino e de diabólico no homem, para retomar por opostos a lição em-travessia e em-diferença de Guimarães Rosa no Grande sertão: Veredas.

Nos momentos muito especiais da vida sentimental e intelectual, Dona Dirce, em "tête-à-tête sombre et limpide", como versejou Charles Baudelaire, corroborava as palavras finais do romance de Rosa: "O senhor é um homem soberano, circunspecto. Amigos somos. Nonada. $\mathrm{O}$ diabo não há! É o que eu digo, se for... Existe é homem humano. Travessia." A que acoplo, para que se bem entenda o que seja o humano em Guimarães Rosa, esta frasezinha que retiro da página 568 da minha edição do romance: "Eu tinha medo de homem humano". Esse medo tem de ser contextualizado. É despertado no protagonista por ter estado em contato com "amigos bondosos, se ajudando uns aos outros com sinceridade nos obséquios e arriscadas garantias, mesmo não refugando a sacrifícios para socorros".

O sentimento do humano em dona Dirce nunca foi bondoso, desde que também se esclareça o contexto da minha afirmação. Também ela tinha medo de homem humano. Por não ser desumana e ser pessoa finíssima e educada, uma personagem de Marcel Proust incapaz de escancarar uma grosseria em público, ${ }^{3}$ eu sempre entendi suas mais secretas e perigosas opiniões (viver é perigoso) através de alguns lapsus linguae. Seus significativos instantes de desumanidade pública.

A recorrência dos lapsus linguae no falar de dona Dirce representava certa brejeirice na fala por vezes aérea, embora sempre afável da mestra. Eu não caía nessa armadilha de sorriso de Mona Lisa. Como não sei alemão, lembro meu Freud em francês: Le mot d'esprit et ses rapports avec l'insconscient. Dou-lhes um exemplo real, evidentemente indiscreto.

Que me perdoe uma de suas melhores discípulas, Evelina, se por acaso faço a leitura duma situação embaraçosa por que dona Dirce, na qualidade de examinadora em banca de mestrado na PUC-RJ, nos fez passar. Evelina se preparava e fora preparada por Dona Dirce para escrever tese de mestrado sobre Guimarães Rosa. Não conseguia escrevê-la, por mais que se esforçasse. O prazo ditatorial de entrega do trabalho ameaçava que nem a foice da morte. Entregue a tese até tal data, ou sua cabeça será decepada. Evelina resolve, então, trabalhar um romance desconhecido e certamente nenhuma obra-prima, mas bastante importante e significativo daquele trágico momento que a maioria dos brasileiros viveu 
nos anos de chumbo da ditadura militar.

Evelina escreve tese de mestrado, a que intitula corajosamente de Supercaos $^{4}$, sobre o romance pop PanAmérica (1967), do paulista José Agrippino de Paula. Para suavizar a desmedida na transição da obra-prima de Rosa para a obra apenas significativa de José Agrippino, Evelina lança mão de estratagema bastante feliz. Resolve considerar o romance PanAmérica como altamente representativo da produção literária brasileira nos últimos 15 anos.

As primeiras frases da arguição de Dona Dirce causam alvoroço em Evelina e se refletem no rosto angustiado da mestranda. Dona Dirce não tinha engolido a estratégia. E sua fala flutuava na sala da PUC como claro enigma, para retomar a expressão de Drummond. Em lugar de se referir à produção dos últimos 15 anos como contexto, Dona Dirce situa o romance na história da literatura brasileira, cometendo um lapsus linguae altamente comprometedor. PanAmérica, começa ela por afirmar, é representativo da produção literária brasileira dos últimos 150 anos, ou seja, de toda a literatura escrita no período nacional, de que fazem parte tanto Machado de Assis quanto Guimarães Rosa.

Eis o modo insolente e enviesado que a professora encontrou para abrir sua arguição e dizer de modo fino, educado e carinhoso que o objeto da tese escapava-lhe por entre os 150 anos da produção literária brasileira, embora o romance fosse bom se o considerasse na perspectiva dos últimos 15 anos. De modo fino, educado e carinhoso, a mestra falava em público de sua decepção, se me permitem ser o anti-Proust, a abrir o jogo postumamente e a usar palavra grosseira. Na hora, tomei a liberdade de desfazer o equívoco, insistindo, é claro, apenas no caráter específico e momentâneo do lapsus linguae: um engano por parte da mestra, perfeitamente perdoável. Apenas um deslize na leitura da proposta da tese. Dona Dirce aceitou a correção e sorriu, agora, sim, com o sorriso enigmático de Mona Lisa. O restante da arguição e da defesa voltou a correr muito bem. Evelina merecia, mereceu e ainda merece todos os elogios da banca.

Aproveito a deixa para confessar que sei (sem, na verdade, ter certeza absoluta) que Dona Dirce nunca se interessou pelos meus escritos de criação literária. Não se trata de problema particular dela, mas o de toda uma geração de notáveis professores/pesquisadores/críticos das principais universidades brasileiras, nascidos na segunda década do século 20 . Todos e todas teriam medo de Virginia Woolf, caso a romancista inglesa tivesse sido contemporânea deles e delas. Eles e elas foram formados pelo 
formidável impacto do multifacetado Modernismo e se lançaram com unhas e dentes no conhecimento do que havia de equivalente e de mais responsável e poderoso no nosso século 19.

Assim como eles e elas se descuidaram dos pré-modernistas (que o digam os admiradores de, entre outros, João do Rio e Lima Barreto), descuidaram-se também dos pós-modernistas, ou seja, dos escritores que começaram a publicar seus livros a partir dos anos 1970.

Quero deixar claro que não se trata de reivindicação mesquinha da minha parte ou de insolência despropositada da parte dela e dos colegas de geração. Trata-se pura e simplesmente de reconhecer na atitude crítica deles e delas a responsabilidade que toda assinatura pessoal carrega, como frisei anteriormente ao restaurar a distinção desfeita entre docente e discente. A assinatura de Dona Dirce, quando não vem inserida numa pequena comunidade de pares, é um bem solitário e privado, a ser preservado e zelado com integridade profissional; ela só é aposta a escrito crítico de grande responsabilidade.

A mestra leu algo que merece ser incluído no cânone universal das Belles lettres e resolve dedicar muito do seu parco tempo de silêncio, abandono e solidão à tarefa feliz e ingrata de decifrá-lo e explicá-lo, justificando o seu valor.

Essa geração, sua geração - no orgulho de desbravadora dum campo desprezado, embora importantíssimo e fertilíssimo do conhecimento acadêmico - exige o direito inquestionável de exclusividade para a assinatura pessoal e solitária que, no entanto, é compartilhada com muitos quando na cena pública, ou seja, na sala de aula e no produto das atividades extracurriculares coletivas. Neste caso, a assinatura amplifica a atitude de grande generosidade e afeto maior daquela que é indubitavelmente a maior mestra acadêmica de sua geração. 


\section{NOTAS}

${ }^{1}$ Do livro acima citado, retiro esta definição: a "unidade didática" se apresenta como "uma divisão da matéria de ensino, bastante ampla para ser significativa e bastante concentrada para ser apanhada como um todo".

${ }^{2}$ A expressão foi cunhada pelo educador Ivan Illitch, em Deschooling society, no auge das revoluções estudantis dos anos 1960. Cf.: "Acredito no movimento. Não acredito que ninguém possa aprender nada sentado, calado, imóvel e passivo, ao lado de outros moscas-mortas, absorvendo como uma esponja a pseudo-sabedoria que um professor despeja." Conheci pessoalmente o educador e pude ler seus livros quando ensinava na Universidade do Novo México, em Albuquerque.

${ }^{3}$ A respeito de Madame de Cambremer, se diz no romance de Proust que "son nom finit jusqu'à temps".

${ }^{4}$ A tese foi publicada em primeira edição pela Civilização Brasileira e em segunda pela Editora da Universidade Federal de Minas Gerais.

Recebido em: 14 de outubro de 2016

Aceito em: 20 de novembro de 2016 